\title{
Potential for Seed Transmission of Verticillium longisporum in Oilseed Rape (Brassica napus)
}

\author{
Xiaorong Zheng, Daniel Teshome Lopisso, Alice Bisola Eseola, Birger Koopmann, and Andreas von Tiedemann ${ }^{\dagger}$ \\ Section of Plant Pathology and Crop Protection, Department of Crop Sciences, Georg August University, 37077 Göttingen, \\ Germany
}

\begin{abstract}
Verticillium longisporum is a soilborne vascular fungal pathogen that has spread throughout the European oilseed rape cultivation area since the 1980s and was detected in canola fields in Canada in 2014. In a series of greenhouse and field inoculation experiments using $V$. longisporumresistant and susceptible cultivars of winter and spring types of oilseed rape, the present study investigated the potential of $V$. longisporum dissemination by seeds of Brassica napus. Greenhouse inoculation studies with a DsRed-labeled isolate of $V$. longisporum confirmed the systemic growth of the pathogen from roots to seeds. Further monitoring of plant colonization in the greenhouse with a species-specific real-time polymerase chain reaction assay verified the pathogen growth from roots to stem bases, pods, and seeds in root-inoculated plants. The frequency of recovery of viable colonies of $V$. longisporum from seeds harvested from greenhouse-grown inoculated plants ranged from 0.08 to $13.3 \%$. The frequency of seed transmission in the greenhouse differed in oilseed rape cultivars varying in susceptibility to $V$. longisporum. Subsequent studies on transmission of the disease into the offspring revealed that only 1.7 to $2.3 \%$ of plants showed disease symptoms as confirmed by the formation

of microsclerotia in the stems. Results from field-grown plants differed from the greenhouse studies. The degree of seed transmission in the field was dependent on the crop type. Although only low concentrations of DNA of $V$. longisporum were detectable in seeds harvested from severely infected winter oilseed rape, significantly greater concentrations of fungal DNA were found in seeds of spring-type oilseed rape, at similar soil conditions and inoculum densities. Correspondingly, plating seeds that were harvested from infected plants on agar yielded viable $V$. longisporum colonies only from seeds of the spring-type but not of the winter-type plants. Lack of seed infection in the winter-type crop was confirmed in two seasons. Equally, none of the offspring grown from seeds from severely diseased winter oilseed rape plants developed symptoms of Verticillium stem striping. The results suggest that the rate of seed transmission of $V$. longisporum depends on the degree of plant colonization, which is significantly faster under greenhouse than field conditions and in a spring-sown crop compared with an autumn-sown oilseed rape crop. According to our studies, disease transmission by seeds from European winter oilseed rape production cannot be confirmed.
\end{abstract}

Verticillium species are soilborne ascomycetes that commonly cause wilting, stunting, chlorosis, vascular discoloration, and premature senescence of more than 200 plant species (Depotter et al. 2016). $V$. longisporum has become a major pathogen in oilseed rape (Brassica napus) after establishment in the oilseed rape production regions in Europe since the 1980s and in Canada since 2014 (Canadian Food Inspection Agency 2017; Gladders et al. 2011; Karapapa et al. 1997; Zeise and von Tiedemann 2002). In Asia, this pathogen has been only reported in Chinese cabbage thus far (Yu et al. 2015). The infection process of $V$. longisporum is similar to that of $V$. dahliae, both of which induce monocyclic vascular diseases (Eynck et al. 2007; Klosterman et al. 2011). Under field conditions, $V$. longisporum germinates from microsclerotia and colonizes the roots of winter-sown oilseed rape soon after sowing in the autumn (Zheng et al. 2019). Disease symptoms occur only at the beginning of ripening and consist of stem striping, although no wilting symptoms can be observed on oilseed rape infected with $V$. longisporum as commonly found for Verticillium diseases on other hosts. Therefore, the disease was named Verticillium stem striping (Depotter et al. 2016). Shortly before harvest, black-pigmented microsclerotia form under the epidermis and in the stem pith (Knüfer et al. 2017). Yield losses caused by V. longisporum infection are estimated to range between 10 and $50 \%$ in fields with severe disease incidence (Dunker et al. 2008; Eastburn and Paul 2007). However, no significant effect of infection by this pathogen on seed quality, such as seed weight, oil content, and oil composition, has been reported thus far (Dunker et al. 2008).

\section{${ }^{\dagger}$ Corresponding author: A. von Tiedemann; atiedem@gwdg.de}

The author(s) declare no conflict of interest.

Accepted for publication 24 January 2019.

(c) 2019 The American Phytopathological Society
Although the modes of root infection of $V$. longisporum in oilseed rape are well understood (Eynck et al. 2007; Zeise and von Tiedemann 2001), the potential of pathogen transmission from one season to the next or to new cropping areas by seeds requires further investigation. Vascular fungi, such as $V$. dahliae and Fusarium oxysporum, cause systemic infection, which potentially enables the pathogen to reach the seeds via the vascular system, a pathway that can be influenced by the plant genotype (Karajeh 2006). In an earlier report, $V$. longisporum was not isolated from seeds harvested from diseased $B$. napus plants (Zhou et al. 2006). Although no clear evidence for seed transmission of $V$. longisporum on oilseed rape has been provided thus far, seed transmission of $V$. dahliae in other host plants such as sunflower, olive, cotton, eggplant, tomato, spinach, and lettuce has been verified by molecular analysis or seed assays, with infection rates ranging from 16 to $66 \%$ of seeds harvested from diseased plants (Göre et al. 2011; Kadow 1934; Karajeh 2006; Snyder and Wilhelm 1962; Vallad et al. 2005; Zhang et al. 2018). In addition, seeds of spinach were shown to transfer microsclerotia of $V$. dahliae into the soil and cause Verticillium wilt in the subsequent lettuce culture (Short et al. 2015).

$V$. longisporum has been reported on plants in previously uninfected areas and even in regions with a short history of oilseed rape cultivation (own observation). Seed transmission could be a potential means for the long-distance spread of this pathogen. Understanding the risk of seed transmission of $V$. longisporum in oilseed rape is also essential for understanding the epidemiology of Verticillium stem striping in present disease hot spots. The objectives of the study were (i) to explore whether $V$. longisporum is detectable on seeds of B. napus plants infected with $V$. longisporum, (ii) to estimate the probability of seed transmission of $V$. longisporum to the offspring and (iii) to assess the impact of oilseed rape cropping types on seed transmission.

\section{Materials and Methods}

Plant material and experimental design of greenhouse and field experiments. To determine seed infection with $V$. longisporum, 
greenhouse experiments were conducted with a two-factorial treatment design consisting of two B. napus winter oilseed rape cultivars Falcon (Norddeutsche Pflanzenzucht Hans-Georg Lembke KG [NPZ]) and Treffer (KWS Saat SE), two spring-type cultivars Visum and OP-DLE 7 (NPZ), and two inoculation treatments. Experiments were conducted with three replicates consisting each of nine (winter-type) or five (spring-type) plants. Seeds confirmed by real-time polymerase chain reaction (PCR) (fungal DNA) and plating on nutrient agar to be free of contamination with $V$. longisporum were surface sterilized with $70 \%$ ethanol for $2 \mathrm{~min}$ and subsequently rinsed twice with sterilized double-distilled water $\left(\mathrm{ddH}_{2} \mathrm{O}\right)$. Seeds were then sown in multipot trays $(3 \times 3 \times 6 \mathrm{~cm}$ for each pot) filled with quartz sand and grown in the greenhouse at $22 \pm 2{ }^{\circ} \mathrm{C}$ for 14 days. Winter-type plants were vernalized for 10 weeks at $4{ }^{\circ} \mathrm{C}$ before inoculation. During vernalization, a fertilizer solution of $3 \mathrm{~g} /$ liter of Hakaphos blau (Compo Expert) was applied twice. All experiments were repeated with an identical design. To confirm the identity of reisolated $V$. longisporum, four plants of both winter oilseed rape cultivars from the first experiment were additionally inoculated with a DsRed-labeled strain of $V$. longisporum (isolate VL43; Zeise and von Tiedemann 2001, 2002).

To verify seed infection of $V$. longisporum under field conditions, two large-scale field experiments were conducted with winter oilseed rape in the seasons 2015/2016 (cultivar Falcon) and 2016/2017 (cultivar Aristoteles; Limagrain $\mathrm{GmbH}$ ) and one field experiment with spring oilseed rape plants (cultivar Visum) in 2016. The three experimental sites were located in close proximity in the northwest of

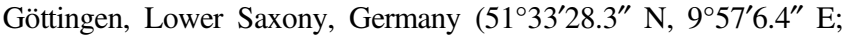
$51^{\circ} 34^{\prime} 10.1^{\prime \prime} \mathrm{N}, 9^{\circ} 55^{\prime} 8.7^{\prime \prime} \mathrm{E}$; and $51^{\circ} 33^{\prime} 31.9^{\prime \prime} \mathrm{N}, 9^{\circ} 55^{\prime} 9.8^{\prime \prime} \mathrm{E}$, respectively). The experiments with winter oilseed rape had a randomized block design with four replicates (plot size $2.5 \times 16 \mathrm{~m}$ ). Spring-type oilseed rape was grown in a miniplot field experiment (plot size $2 \times 2.5 \mathrm{~m}$ ) with randomized four replicates. All experiments were conducted on soils inoculated with $15 \mathrm{~g} / \mathrm{m}^{2} \mathrm{~V}$. longisporum inoculum (ground infected straw) incorporated into the soil (upper 5-cm layer) immediately before sowing, as described previously (Knüfer et al. 2017). Seeds were collected from mature diseased plants at growth stage (GS) 90 (beginning of senescence), showing microsclerotia formation in the stems. Plant GSs were assessed following the identification key described by Weber and Bleiholder (1990) and Lancashire et al. (1991).

Fungal inoculum preparation and inoculation procedure in the greenhouse. $V$. longisporum (isolate VL43) obtained from a diseased B. napus plant (Zeise and von Tiedemann 2001, 2002) and a DsRed-labeled VL43 isolate were used for the greenhouse experiments. The DsRed-labeled strain was generated via Agrobacterium tumefaciens-mediated transformation according to Eynck et al. (2007) using the plasmid pCAMBIA-DsRed kindly provided by Maria Eckert (Rothamsted Research, U.K.) (Eckert et al. 2005). A conidial suspension of VL43 that had been stored in $25 \%$ glycerol at $-80^{\circ} \mathrm{C}$ was used to initiate fresh cultures. For preparation of the fungal culture, a stock conidial suspension was plated on potato dextrose agar containing $250 \mathrm{ppm}$ of streptomycin and incubated at $22^{\circ} \mathrm{C}$ for 10 days. Conidia were harvested by flooding the plate with sterilized $\mathrm{ddH}_{2} \mathrm{O}$ and sweeping the colony surface with a sterilized loop. The resulting suspension was filtered through sterilized gauze to remove mycelia.

Roots of seedlings were washed, cut with sterile scissors, and subsequently inoculated by dipping in $1 \times 10^{7} \mathrm{CFU} / \mathrm{ml}$ of conidia suspension or mock-treated in water for $30 \mathrm{~min}$. The treated plants were transplanted into plastic (1.5-liter) pots with sterilized soil/sand mixture (3:1) and kept in the greenhouse with a $16-\mathrm{h}$ photoperiod per day at $22 \pm 2{ }^{\circ} \mathrm{C}$.

Quantification of $\boldsymbol{V}$. longisporum by real-time PCR. Lyophilized stem bases (between the uppermost root and lowest leaf insertion) and pods collected at GS 80 (beginning of ripening) or air-dried seeds collected at GS 90 (beginning of senescence) were ground to a fine powder. Total DNA was extracted from $50 \mathrm{mg}$ of ground sample using the cetyltrimethylammonium bromide (CTAB) method (Brandfass and Karlovsky 2008). Briefly, ground samples were homogenized in $1 \mathrm{ml}$ of CTAB with $2 \mu \mathrm{l}$ of $\beta$-mercaptoethanol and $1 \mu l$ of proteinase $\mathrm{K}$. The mixture was sonicated for $5 \mathrm{~s}$ and incubated for $10 \mathrm{~min}$ at $42^{\circ} \mathrm{C}$ and subsequently for $10 \mathrm{~min}$ at $65^{\circ} \mathrm{C}$. For degradation of RNA, $1.5 \mu$ l of RNase was added and incubated for $15 \mathrm{~min}$ at $37^{\circ} \mathrm{C}$. For isolation of DNA from the mixture, $800 \mu \mathrm{l}$ of chloroform/isoamylalcohol (24:1) was added and incubated on ice for $10 \mathrm{~min}$. After centrifugation at $16,099 \times g$ for $10 \mathrm{~min}$, the supernatant was mixed in $200 \mu \mathrm{l}$ of $30 \%$ polyethylene glycol and $100 \mu \mathrm{l}$ of $5 \mathrm{M} \mathrm{NaCl}$ for precipitation. The DNA pellet, after centrifugation for $5 \mathrm{~min}$, was washed with $70 \%$ ethanol. The DNA pellet was then dried in a centrifugal concentrator for $10 \mathrm{~min}$ at $30^{\circ} \mathrm{C}$ and dissolved overnight in $100 \mu l$ of Tris-EDTA buffer at $4^{\circ} \mathrm{C}$.

The total extracted DNA was stained with Midori Green and analyzed with $1 \%$ agarose gel electrophoresis. A CFX384 real-time PCR thermal cycler (Bio-Rad Laboratories Inc.) was used for the amplification and quantification of $V$. longisporum DNA using $\beta$-tubulin forward (5'-GCAAAACCCTACCGGGTTATG-3') and reverse primers (5'-AGATATCCATCGGACTGTTCGTA-3') (Debode et al. 2011). The $10 \mu \mathrm{l}$ PCR mix consisted of $5 \mu$ l of premix (qPCRBIO SyGreen Mix Lo-Rox; Nippon Genetics Europe GmbH), $0.4 \mu \mathrm{M}$ of each primer, and $1 \mu$ l of template DNA. The PCR program entailed a 3-min initial denaturation step, followed by 40 cycles with a denaturation step $\left(5 \mathrm{~s}\right.$ at $\left.95^{\circ} \mathrm{C}\right)$, an annealing step $\left(15 \mathrm{~s}\right.$ at $\left.68^{\circ} \mathrm{C}\right)$, and subsequent extension $\left(15 \mathrm{~s}\right.$ at $\left.72^{\circ} \mathrm{C}\right)$. Fluorescence was detected after each elongation step and the program was completed with a final elongation step of $2 \mathrm{~min}$ at $72^{\circ} \mathrm{C}$. Melting curve analysis was performed at $95^{\circ} \mathrm{C}$ for $10 \mathrm{~s}$, followed by a $55^{\circ} \mathrm{C}$ step for $10 \mathrm{~s}$ and subsequent measurements within a range of 65 to $95^{\circ} \mathrm{C}$ with $0.5^{\circ} \mathrm{C}$ temperature increments every $5 \mathrm{~s}$. The real-time PCR assay was completed for all samples using three biological and three technical replicates, and data were analyzed using CFX Manager software (Bio-Rad Laboratories Inc.).

Plating assay for seed infection analysis. For analysis of seed infection with $V$. longisporum, 150 seeds per treatment $(2$ cultivars $\times 2$ inoculations $) \times 3$ replicates $(1,800$ seeds in total) were harvested from the greenhouse-grown diseased winter-type plants and 160 seeds per treatment $(2$ cultivars $\times 2$ inoculations $) \times 3$ replicates $(1,920$ seeds in total) were harvested from spring-type plants. Sampling was identical in both replicated experiments.

Seeds from the field were sampled from 12 diseased plants of spring oilseed rape ( 240 seeds per plant, 2,880 seeds in total), from nine diseased plants of winter oilseed rape in season 2015/2016 (240 seeds per plant, 2,160 seeds in total), and from eight diseased plants of winter oilseed rape in season 2016/2017 (280 seeds per plant, 2,240 seeds in total). All seeds were surface disinfested with $3 \%$ sodium hypochlorite for $2 \mathrm{~min}$. Sterilized seeds from greenhouse and field-grown plants were plated on synthetic nutrient-poor agar (SNA; Nirenberg 1976) and semi-Verticillium-selective medium, respectively, and incubated at $23^{\circ} \mathrm{C}$ in the dark for 28 days. The modified Verticillium-selective medium consisted of $1.5 \mathrm{~g} / \mathrm{liter}$ of $\mathrm{KH}_{2} \mathrm{PO}_{4}, 4 \mathrm{~g} /$ liter of $\mathrm{K}_{2} \mathrm{HPO}_{4}, 1 \mathrm{ml} /$ liter of Tergitol, $2 \mathrm{~g} /$ liter of sodium polypectate, $2 \mathrm{ml} /$ liter of salt solution $\left(100 \mathrm{~g} /\right.$ liter of $\mathrm{KH}_{2} \mathrm{PO}_{4}$, $50 \mathrm{~g} / \mathrm{liter}$ of $\mathrm{KCl}, 50 \mathrm{~g} / \mathrm{liter}$ of $\mathrm{MgSO}_{4}, 1 \mathrm{~g} /$ liter of $\mathrm{FeSO}_{4}$, and $200 \mathrm{~g} /$ liter of $\mathrm{NaNO}_{3}$ ), $60 \mathrm{mg} /$ liter of chloramphenicol, $60 \mathrm{mg} /$ liter of chlortetracycline, $60 \mathrm{mg} / \mathrm{liter}$ of streptomycin, and $6 \mathrm{mg} / \mathrm{liter}$ of biotin. The presence of $V$. longisporum colonies was detected with a light microscope. Seeds harvested from plants (50 seeds per plants, 200 seeds in total) inoculated with the DsRed-expressing strain of $V$. longisporum were examined using a Leica Leitz DMRB fluorescence microscope with a bandpass Cy3.5/DsRed filter system (excitation filter: $565 \mathrm{~nm} /$ $30 \mathrm{~nm}$, emission filter: $620 \mathrm{~nm} / 60 \mathrm{~nm}$; AHF Analysentechnik AG).

Second-generation seed testing in the greenhouse. In the greenhouse, 24 diseased plants were selected from each of the two winter oilseed rape cultivars Falcon and Treffer for analysis of disease development in the offspring. Three biological replicates per cultivar each consisting of 120 seeds harvested from eight plants were selected for planting, resulting in a total of 720 plants examined for evidence of seed transmission.

In addition, 60 plants grown from seeds collected from each of eight field-grown diseased plants (cultivar Aristoteles, experiment 2016/2017) were included in this study, resulting in a total of 480 plants. As a control, three replicates each consisting of 60 plants grown from healthy seeds (laboratory stored seeds, 180 plants 
in total) were included in the experiment. Seeds harvested from greenhouse-inoculated or field-infected plants were surface sterilized with $3 \%$ sodium hypochlorite for $2 \mathrm{~min}$ and then sown in multipot trays filled with a sterilized soil/sand mixture (3:1). Plants were vernalized as described above and transplanted into pots $(11 \times 11 \times$ $12 \mathrm{~cm}$ ) filled with sterilized soil/sand mixture (3:1) and grown for 6 months in the greenhouse. After harvest (GS 99), the presence of microsclerotia on subepidermal and pith tissues of stems was examined by naked eye and microscopic observation.

Statistical analysis. All data were analyzed using XLSTAT2018 software. Before testing for statistical significance, a probability plot with the Shapiro-Wilk test was used to test the normality of the distribution of the data. Nonnormally distributed data were analyzed with the Kruskal-Wallis test (two-tailed), and the Conover-Iman procedure at $P=0.05$ was applied for multiple pairwise comparisons. Results are presented as means \pm standard error at the $5 \%$ significance level.

\section{Results}

Quantification of $V$. longisporum DNA in stem bases, pods, and seeds of winter and spring oilseed rape in the greenhouse. $V$. longisporum was detected in stem bases, pods, and seeds of mature greenhouse-grown diseased winter oilseed rape plants but not in mock-inoculated plants by real-time PCR (Fig. 1). In Falcon, which is relatively more susceptible to $V$. longisporum (Lopisso et al. 2017a), significantly higher quantities of fungal DNA accumulated in pods and seeds than in Treffer (Fig. 1, B and C). However, this result was not statistically reproduced in experiment II as a result of the low infection rate. The concentrations of $V$. longisporum DNA detected in stem bases and pods were about fourfold to 30 -fold greater than in the seeds.

Similar to winter oilseed rape, DNA of $V$. longisporum was detected in stem bases, pods, and seeds of greenhouse-grown spring oilseed rape plants (Fig. 1), whereas none of the mock-inoculated plants or their seeds were contaminated by $V$. longisporum.

Isolation of $\boldsymbol{V}$. longisporum from seeds of greenhouse-grown oilseed rape. Ten days after incubation of seeds harvested from greenhouse plants on agar medium, no colonies of $V$. longisporum grew from seeds harvested from mock-inoculated plants of all cultivars, while at the same time white colonies of $V$. longisporum were isolated from seeds harvested from diseased plants of all cultivars of winter and spring oilseed rape. These colonies were further incubated and produced dark pigmented microsclerotia 28 days after incubation (Fig. 2). Observation of the verticillate conidiophores and elongated conidia using a light microscope confirmed the identity
A

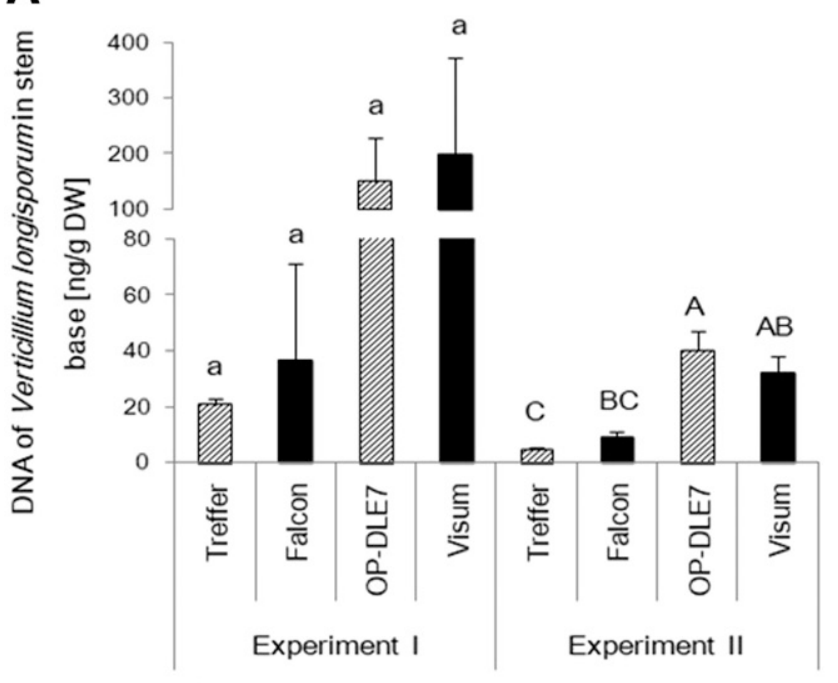

B

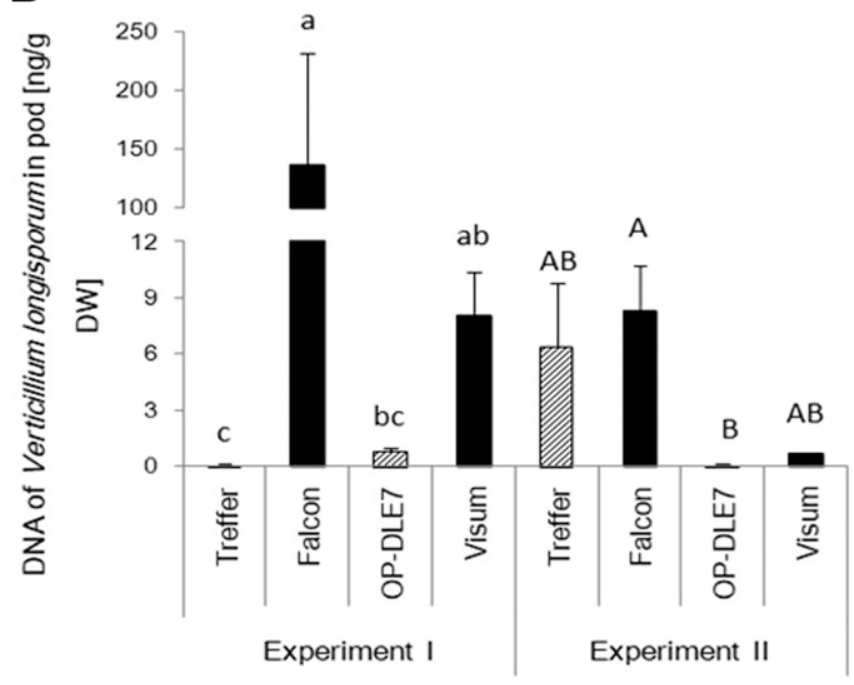

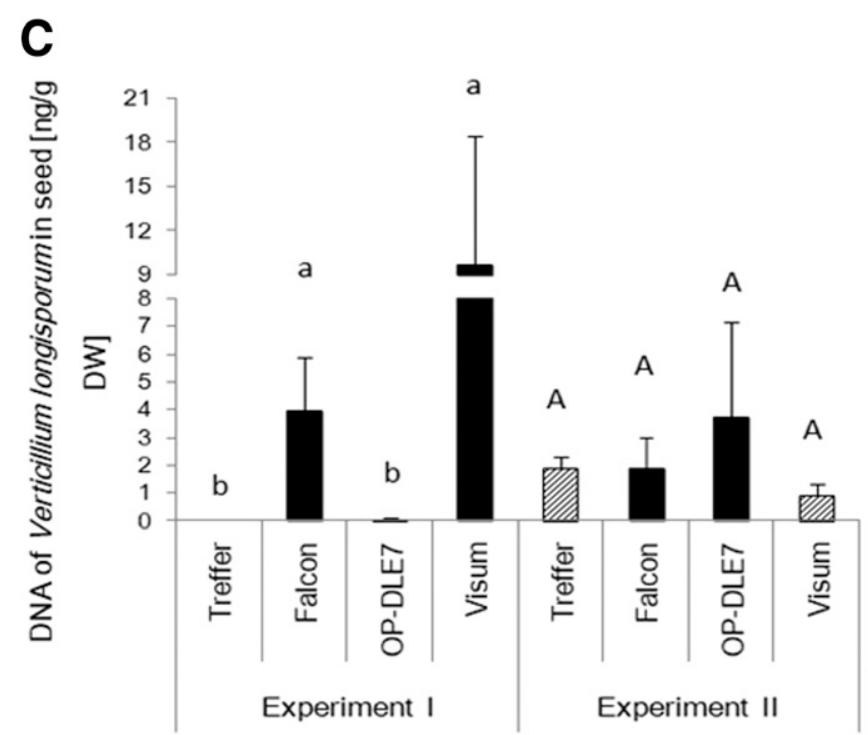

Fig. 1. Quantification of Verticillium longisporum DNA in A, stem bases, B, pods, and C, seeds of winter and spring oilseed rape inoculated with V. longisporum in the greenhouse by real-time polymerase chain reaction. Cultivars Treffer and Falcon are winter oilseed rape; OP-DLE7 and Visum are spring oilseed rape. Stem bases and pods were collected at plant ripening stages (growth stage [GS] 80) and seeds were collected at the beginning of senescence (GS 90). No amplification signals were recorded in control plants (i.e., the values were zero and are not shown). Bars indicate standard errors of means. Different letters indicate significant differences between treatments (Kruskal-Wallis test, $P<0.05)$. $\mathrm{DW}=$ dry weight. 
of the cultures as $V$. longisporum. The highest frequency of seed infection with $V$. longisporum was found in winter oilseed rape cultivar Falcon, with 13 and $7 \%$ in experiments I and II, respectively (Table 1).

The systemic growth of $V$. longisporum from infected roots to seeds was verified by plating the seeds harvested from plants rootdip inoculated with a DsRed-labeled strain of V. longisporum on SNA. Fungal colonies with similar morphological characteristics as described above were observed on the agar plates around the seeds. Under the fluorescence microscope with a Cy3.5/DsRed filter system, hyphae and conidia emitted red fluorescence. Dark pigmented microsclerotia were also observed among dense fluorescing hyphae (Fig. 3). Thus, fungal isolates retrieved from surface-sterilized seeds were confirmed to be identical to the $V$. longisporum strain, which had been used for inoculation of the plant roots.

Occurrence of $\boldsymbol{V}$. longisporum stem striping in the offspring from plants inoculated in the greenhouse. Only 1.7 and $2.3 \%$ of plants of cultivars Treffer and Falcon, respectively, grown from seeds harvested from diseased winter oilseed rape plants after inoculation in the greenhouse also displayed typical Verticillium stem striping symptoms, including the presence of microsclerotia in roots, under the stem epidermis and in the stem pith.

Seed infection with $V$. longisporum on field-grown $B$. napus and transmission to the offspring. Although the seeds from the field were collected from plants severely affected by the disease, the frequencies of isolated viable fungal colonies and quantities of $V$. longisporum DNA in seeds were substantially smaller than in greenhouse-grown inoculated plants (Table 2). The concentrations of fungal DNA detected in seeds of spring-type oilseed rape were significantly larger than in seeds of winter oilseed rape, even though these plants were grown in soils infested with $V$. longisporum at similar inoculum rates.

Although real-time PCR quantification of $V$. longisporum in seeds from field-grown winter oilseed rape indicated very low levels of infection (Table 2), attempts to isolate the pathogen from these samples by agar plating failed. This result was confirmed with a large number of seed testing in two seasons for DNA and reisolation of viable colonies of $V$. longisporum. In contrast, about $3 \%$ of seeds from field-grown spring oilseed rape plants yielded viable colonies of $V$. longisporum on nutrient agar (Table 2).

Since the study focus was on winter oilseed rape as the predominant type of oilseed rape cultivation in Europe, 480 seeds collected from diseased winter oilseed rape plants in the field were planted in the greenhouse and cultivated for 6 months until maturity to test for seed transmission of the disease to the offspring. As a result, none of the 480 plants tested showed any disease symptoms until the end of observation (GS 99).

\section{Discussion}

The use of healthy seeds is an essential practice to safeguard the productivity of crops. Seeds may also serve as vehicles for the transmission of pathogens from one season to the next or the dissemination from one location to another (Maruthachalam et al. 2013). Oilseed rape represents the second largest crop of world oilseed production and the seeds are traded widely among Europe, Asia, and the Americas (U.S. Department of Agriculture 2018). Neither the systemic growth of $V$. longisporum from the roots to the seeds nor the potential spread of $V$. longisporum by seeds at the local, regional, or long-distance scale have previously been explored. Because $V$. longisporum grows systemically in the plant vasculature, it may
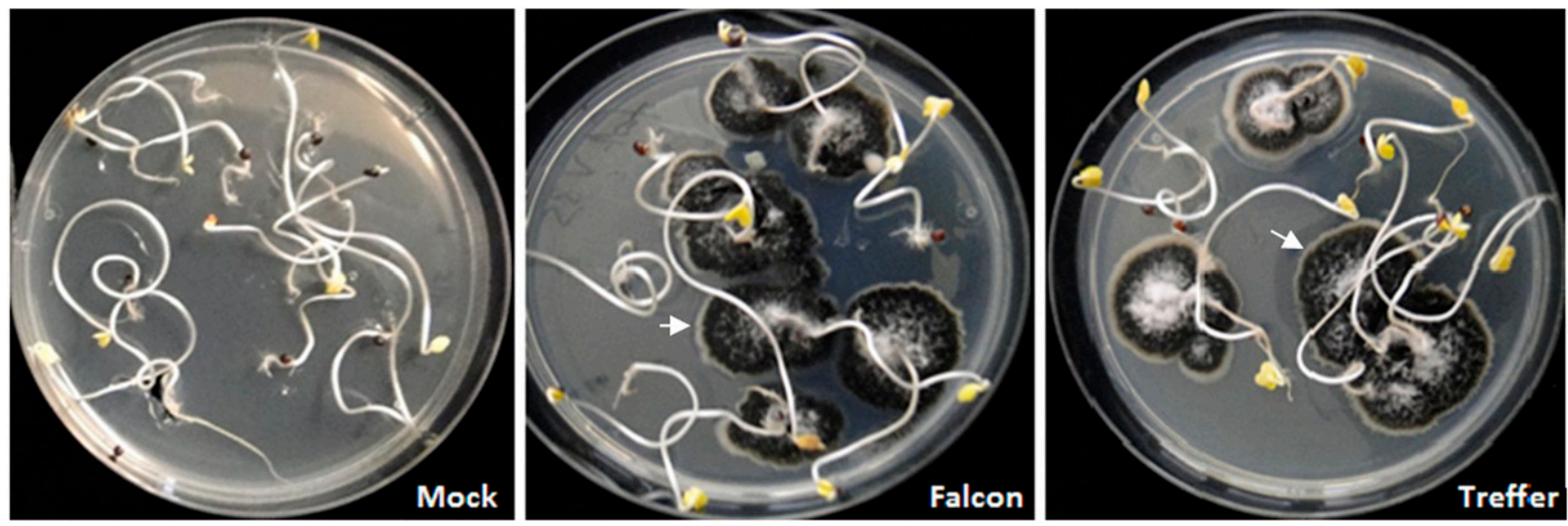

Fig. 2. Plating assay for determination of seed infection with Verticillium longisporum (VL43) in two winter oilseed rape cultivars infected with a DsRed-labeled strain of V. longisporum under greenhouse conditions. Surface-sterilized seeds were incubated on synthetic nutrient-poor agar for 28 days at $23^{\circ} \mathrm{C}$ in the dark. Typical colonies of $V$. longisporum with dark microsclerotia are marked with arrows.

Table 1. Frequency of viable Verticillium longisporum colonies isolated by agar plating from seeds of winter and spring oilseed rape cultivars inoculated with $V$. longisporum isolate VL43 and DsRed-labeled VL43 under greenhouse conditions

\begin{tabular}{|c|c|c|c|c|c|c|}
\hline \multirow[b]{3}{*}{ Cultivar } & & \multicolumn{5}{|c|}{ Seed infection frequency $(\%)^{y}$} \\
\hline & & \multicolumn{3}{|c|}{ Experiment I } & \multicolumn{2}{|c|}{ Experiment II } \\
\hline & & Mock & VL43 & DsRed $\mathrm{VL}^{4} 3^{\mathrm{z}}$ & Mock & VL43 \\
\hline \multirow[t]{2}{*}{ Winter type } & Falcon & $0.00 \mathrm{c}$ & $13.33 \pm 3.00 \mathrm{a}$ & $10.50 \pm 3.86 \mathrm{a}$ & $0.00 \mathrm{c}$ & $6.89 \pm 2.56 \mathrm{a}$ \\
\hline & Treffer & $0.00 \mathrm{c}$ & $0.08 \pm 0.08 \mathrm{bc}$ & $5.50 \pm 2.22 \mathrm{ab}$ & $0.00 \mathrm{c}$ & $1.56 \pm 0.59 \mathrm{ab}$ \\
\hline \multirow[t]{2}{*}{ Spring type } & OP-DLE7 & $0.00 \mathrm{c}$ & $1.46 \pm 0.55 \mathrm{abc}$ & n.d. & $0.00 \mathrm{c}$ & $0.21 \pm 0.21 \mathrm{bc}$ \\
\hline & Visum & $0.00 \mathrm{c}$ & $6.25 \pm 0.63 \mathrm{ab}$ & n.d. & $0.00 \mathrm{c}$ & $1.46 \pm 0.91 \mathrm{abc}$ \\
\hline
\end{tabular}


potentially be capable to invade the inflorescences and seeds, similar to a related pathogen, $V$. dahliae, which has been reported to systematically infect the testa and pericarp of sunflower seed, but not the cotyledons (Sackston 2009; Sackston et al. 1957; Zhang et al. 2018). A previous study demonstrated that no fungal contamination with $V$. longisporum was observed in seed coats or seedlings of infected B. napus plants (Zhou et al. 2006). In contrast, external contamination of seeds harvested from a severely infected oilseed rape crop was confirmed by a study in the United Kingdom (Gladders et al. 2013).

In the present study, experiments under controlled conditions that entailed seed testing for DNA and reisolation of viable colonies of $V$. longisporum confirmed that $V$. longisporum was able to establish in seeds of both winter and spring oilseed rape as a result of systemic colonization of root-inoculated plants. Low amounts of the pathogen DNA were also detected in seeds by real-time PCR and the fungus was isolated from seeds harvested from asymptomatic winter oilseed rape plants, indicating the potential of a latent seed transmission.

The rate of $V$. longisporum infection of seeds in the present study, based on the recovery of viable fungal colonies, ranged from 0.08 to $13.3 \%$ under greenhouse conditions, which was much lower than the incidence of seed infection of $V$. dahliae in lettuce (Vallad et al. 2005). Although plating seeds is an efficient method, a low detection power resulting in a high rate of false-negative results is the disadvantage of this commonly used method (Karajeh 2006). By using the plating method with seeds sampled from field-grown plants, the slower growth of $V$. longisporum compared with saprotrophic fungi represents a general difficulty to detect and isolate the pathogen from seeds. An optimized real-time PCR assay with species-specific primers therefore can provide a more sensitive method to detect and quantify very small amounts of the target fungus in plant tissues (Knüfer et al. 2017; Nazar et al. 1991). With this tool, even the presence of very low amounts of fungal DNA in seeds was detected from field-grown and field-infected winter and spring oilseed rape, indicating the potential presence of $V$. longisporum. However, the quantity of fungal DNA in seeds harvested from field-grown plants was much lower than in the seeds collected from greenhouse-grown diseased plants. Furthermore, the amount of fungal DNA found in the seeds of spring oilseed rape was consistently higher than in winter oilseed rape.

Although the detection of fungal DNA in oilseed rape seeds is an important novel finding, it does not necessarily mean that the disease occurs in the offspring, particularly under field conditions. Accordingly, the quantities of DNA of $V$. longisporum in seeds found in this study were not consistent with the recovery rate of viable colonies of the pathogen or the incidence of disease in the offspring. In contrast to the greenhouse, no transmission of viable $V$. longisporum colonies in the seeds was observed in field-grown winter oilseed rape, while only a very low rate of $V$. longisporum infection was found in spring oilseed rape seeds from the field. More importantly, among a large number of plants derived from seeds collected from severely diseased winter oilseed rape plants in the field, none displayed any $V$. longisporum stem striping symptoms or presence of the fungus until harvest.

There may be several reasons for the discrepancy between DNAbased detection of fungal seed contamination and the rate of fungus
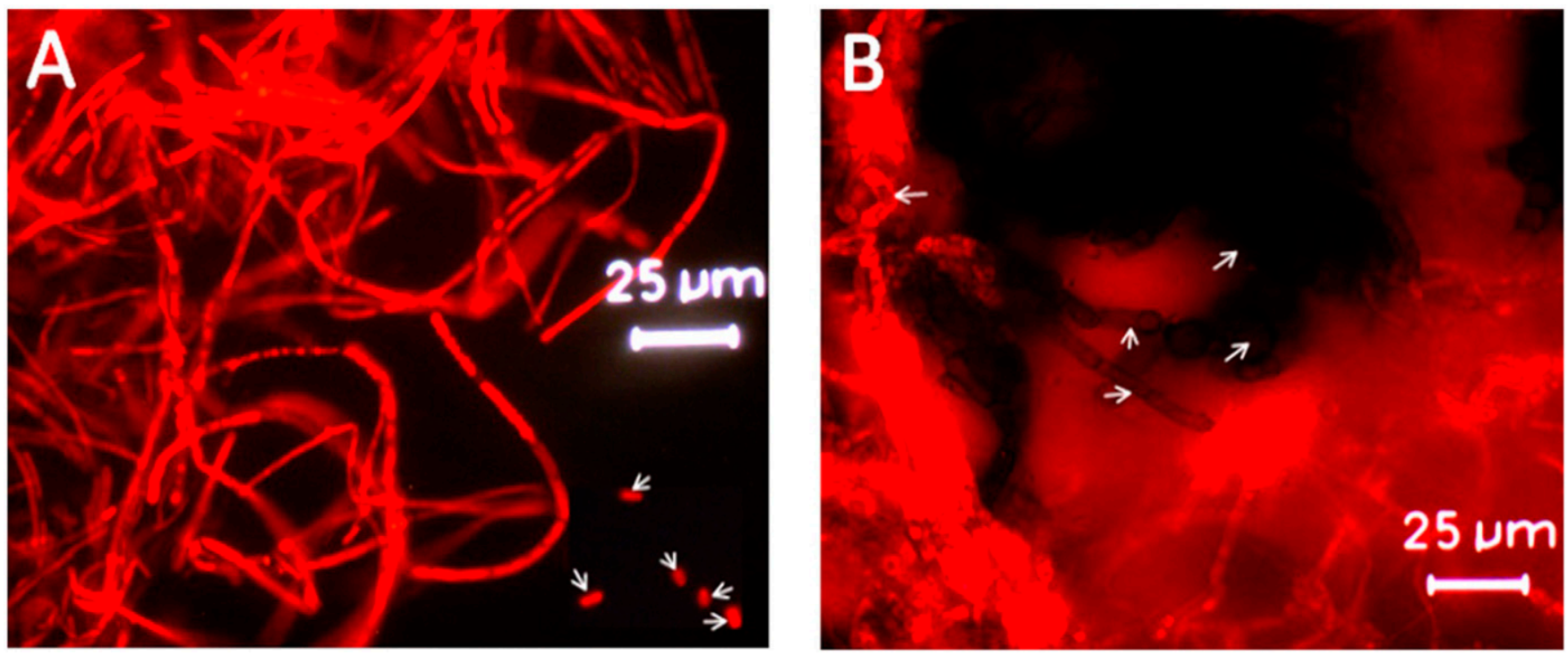

Fig. 3. Confirmation of the identity of Verticillium longisporum reisolated from seeds of winter oilseed rape grown and inoculated under greenhouse conditions by fluorescence microscopy imaging of the DsRed-labeled transformant VL43 strain. A, Hyphae of V. Iongisporum with conidia (arrows). B, Hyphae of V. longisporum with microsclerotia (arrows).

Table 2. Seed infection frequency assessed by agar plating and quantification of Verticillium longisporum DNA in seeds of winter and spring oilseed rape plants grown and infected in the field

\begin{tabular}{llccc}
\hline Field season & \multicolumn{1}{c}{ Crop type } & Number of seeds analyzed & $\begin{array}{c}\text { Seed infection } \\
\text { frequency (\%) }\end{array}$ & $\begin{array}{c}\text { DNA of } \boldsymbol{V} \text {. longisporum in seeds } \\
\text { (ng/g dry weight) }\end{array}$ \\
\hline 2016 & Spring oilseed rape (cultivar Visum) & 2,880 & $3.2 \pm 0.46$ & $1.1 \pm 0.39$ a \\
$2015 / 2016$ & Winter oilseed rape (cultivar Falcon) & 2,160 & No detection & n.d. \\
$2016 / 2017$ & Winter oilseed rape (cultivar Aristoteles) & 2,240 & No detection & $0.3 \pm 0.04 \mathrm{~b}$ \\
\hline
\end{tabular}

${ }^{y}$ Seeds were plated on synthetic nutrient-poor agar. Data represent means \pm standard error. Different letters indicate significant differences between cultivars (Kruskal-Wallis test, $P<0.05$ ). Data represent means of seeds harvested from field experiments from nine plants of winter oilseed rape in the season 2015/ 2016, eight plants of winter oilseed rape in the season 2016/2017, and 12 plants of spring oilseed rape in the season 2016 showing strong microsclerotia formation in stems at growth stage (GS) 90 (beginning of senescence). For agar plating, 280 seeds were tested for each plant.

${ }^{\mathrm{z}}$ For DNA analysis, $50 \mathrm{mg}$ of dried ground seeds from each plant were used. n.d. = not determined. 
and/or disease occurring in the next generation. Using seed samples obtained from diseased plants for real-time PCR detection may lead to a higher estimation of $V$. longisporum contamination owing to externally attached fungal biomass on the seed surface (Short et al. 2015), which may not be viable but are positive by real-time PCR without representing internal seed infection.

Seed contamination and the spread of Verticillium stem striping via seed in the offspring may also be affected by environmental conditions (Sackston 2009). A striking delay in the colonization of $B$. napus with $V$. longisporum in the field differing between autumn- and spring-sown oilseed rape was observed and related to the different soil temperatures during late autumn, winter, and early spring (Zheng et al. 2019). In contrast to the field, V. longisporum invaded and continuously colonized oilseed rape plants in the greenhouse at a constant temperature of $22^{\circ} \mathrm{C}$, leading to disease symptoms in the shoots as early as 28 to 35 days postinoculation (Kamble et al. 2013). The extended time required to colonize the shoots of winter oilseed rape in the field ( $>8$ months) strongly limits the risk of the fungus to reach the pods and seeds before maturity and provides a plausible explanation of why this type of oilseed rape crop fails to produce seeds that are capable of transmitting $V$. longisporum. In contrast, spring-type oilseed rape displayed shoot colonization within about 2 months postseeding, facilitating the fungal invasion of inflorescences, which increases the risk of seed contamination in this crop type, as demonstrated in the present study. Similarly, the relatively high rates of seed infection in greenhouse-grown plants are reflected by the high speed of colonization and the additional induction of stunting by $V$. longisporum (Lopisso et al. 2017b).

No significant difference in colonization of $V$. longisporum was found in stem bases between cultivars of both winter and spring oilseed rape in the ripening stage (GS 80). However, different cultivars had different quantities of $V$. longisporum DNA in pods and seeds, supporting previous reports on quantitative resistance in shoots to $V$. longisporum (Eynck et al. 2009) and indicating that breeding for cultivar resistance may also be an effective means to reduce the risk of seed transmission of this pathogen. Previously, an effect of cultivar was demonstrated for $V$. dahliae in cotton (Göre et al. 2011). However, under greenhouse conditions, V. longisporum was able to colonize seeds of both cultivars and to cause disease in the second generation, regardless of the cultivars' resistance level.

Besides the potential of local and long-distance spread of Verticillium stem striping between oilseed rape fields, seedborne $V$. longisporum may have a direct economic impact on oilseed rape production by causing lower seed quality. However, previous studies have yielded contrasting results. An earlier study showed that there was no effect of $V$. longisporum infection on the 1,000 seed weight and oil content in the field although significant yield losses were observed on individual plants (Dunker et al. 2008). In contrast, a 12 to $24 \%$ reduction of 1,000 seed weight was observed in several field experiments in a study in the United Kingdom when a more than $50 \%$ disease incidence occurred on stems (Gladders et al. 2013). Seed samples containing abnormally small seeds should be prevented from being sown in the field using sieve separation. During storage of harvested seeds or with home-saved seeds, moderate temperature $\left(23 \pm 2^{\circ} \mathrm{C}\right)$ had no adverse effects on the viability of seeds but it may reduce the incidence of $V$. longisporum seed infection, based on a previous report of lettuce seed infection by $V$. dahliae (Vallad et al. 2005). The effectiveness of seed treatment against $V$. longisporum with chemicals is not known. Since commercial oilseed rape fields are planted with seeds commonly treated with fungicides, this appears to be a crucial question in the risk management of $V$. longisporum dissemination by seeds. The application of antagonistic bacteria or fungi may be a further option to manage seedborne V. longisporum (Abuamsha et al. 2011).

The present study has a particular importance for regions where $V$. longisporum has been not recorded thus far in oilseed rape production. This study, for the first time, provides comprehensive data on the role of seeds of $B$. napus in spreading $V$. longisporum. Although there is evidence from this research that transmission of the viable pathogen with seeds is possible under controlled greenhouse conditions, this was not confirmed for winter oilseed rape in the field. However, because of faster plant colonization, the risk of transmission in spring-type oilseed rape cannot be ruled out and thus requires further research, including the potential effects of biological or chemical seed treatments against $V$. longisporum.

\section{Literature Cited}

Abuamsha, R., Salman, M., and Ehlers, R. U. 2011. Differential resistance of oilseed rape cultivars (Brassica napus ssp. oleifera) to Verticillium longisporum infection is affected by rhizosphere colonisation with antagonistic bacteria, Serratia plymuthica and Pseudomonas chlororaphis. Bio Control 56:101-112.

Brandfass, C., and Karlovsky, P. 2008. Upscaled CTAB-based DNA extraction and real-time PCR assays for Fusarium culmorum and F. graminearum DNA in plant material with reduced sampling error. Int. J. Mol. 9:2306-2321.

Canadian Food Inspection Agency. 2017. Pest risk management document: Verticillium longisporum (Verticillium stripe). http://www.inspection.gc.ca/ plants/plant-pests-invasive-species/directives/risk-management/rmd-17-01/ eng/1487004855251/1487004951480.

Debode, J., van Poucke, K., França, S. C., Maes, M., Höfte, M., and Heungens, K. 2011. Detection of multiple Verticillium species in soil using density flotation and real-time polymerase chain reaction. Plant Dis. 95:1571-1580.

Depotter, J. R. L., Deketelaere, S., Inderbitzin, P., von Tiedemann, A., Höfte, M., Subbarao, K. V., Wood, T. A., and Thomma, B. P. H. J. 2016. Verticillium longisporum, the invisible threat to oilseed rape and other brassicaceous plant hosts. Mol. Plant Pathol. 17:1004-1016.

Dunker, S., Keunecke, H., Steinbach, P., and von Tiedemann, A. 2008. Impact of Verticillium longisporum on yield and morphology of winter oilseed rape (Brassica napus) in relation to systemic spread in the plant. J. Phytopathol. 156:698-707.

Eastburn, D. M., and Paul, V. H. 2007. Verticillium wilt. Pages 47-50 in: Compendium of Brassica Diseases. R. S. Rimmer, V. I. Shattuck, and L. Buchwaldt, eds. American Phytopathological Society, St. Paul, MN.

Eckert, M., Maguire, K., Urban, M., Foster, S., Fitt, B., Lucas, J., and HammondKosack, K. 2005. Agrobacterium tumefaciens-mediated transformation of Leptosphaeria spp. and Oculimacula spp. with the reef coral gene DsRed and the jellyfish gene $g f p$. FEMS Microbiol. Lett. 253:67-74.

Eynck, C., Koopmann, B., Grunewaldt-Stoecker, G., Karlovsky, P., and von Tiedemann, A. 2007. Differential interactions of Verticillium longisporum and $V$. dahliae with Brassica napus detected with molecular and histological techniques. Eur. J. Plant Pathol. 118:259-274.

Eynck, C., Koopmann, B., and von Tiedemann, A. 2009. Identification of Brassica accessions with enhanced resistance to Verticillium longisporum under controlled and field conditions. J. Plant Dis. Prot. 116:63-72.

Gladders, P., Richie, F., Babara, D., Clarkson, J., Chantry, T., Taylor, M., and Turner, J. 2013. Importance and management of Verticillium wilt in winter oilseed rape. HGCA Project Report RD-2009-RD-3618. https://cereals.ahdb. org.uk/media/543111/pr512.pdf.

Gladders, P., Smith, J. A., Kirkpatrick, L., Clewes, E., Grant, C., Barbara, D. Barnes, A. V., and Lane, C. R. 2011. First record of Verticillium wilt (Verticillium longisporum) in winter oilseed rape in the UK. New Dis. Rep. 23:8.

Göre, M. E., Erdoğan, O., Altin, N., Aydın, M. H., Caner, Ö. K., Filizer, F., and Büyükdöğerlioğlu, A. 2011. Seed transmission of Verticillium wilt of cotton. Phytoparasitica 39:285-292.

Kadow, K. J. 1934. Seed transmission of Verticillium wilt of eggplants and tomatoes. Phytopathology 24:1265-1268.

Kamble, A., Koopmann, B., and von Tiedemann, A. 2013. Induced resistance to Verticillium longisporum in Brassica napus by $\beta$-aminobutyric acid. Plant Pathol. 62:552-561

Karajeh, M. R. 2006. Seed transmission of Verticillum dahliae in olive as detected by a highly sensitive nested PCR-based assay. Phytopathol. Mediterr. 45:15-23.

Karapapa, V. K., Bainbridge, B. W., and Heale, J. B. 1997. Morphological and molecular characterization of Verticillium longisporum comb, nov., pathogenic to oilseed rape. Mycol. Res. 101:1281-1294.

Klosterman, S. J., Subbarao, K. V., Kang, S., Veronese, P., Gold, S. E., Thomma, B. P. H. J., Chen, Z., Henrissat, B., Lee, Y.-H., Park, J., Garcia-Pedrajas, M. D., Barbara, D. J., Anchieta, A., de Jonge, R., Santhanam, P., Maruthachalam, K., Atallah, Z., Amyotte, S. G., Paz, Z., Inderbitzin, P., Hayes, R. J., Heiman, D. I., Young, S., Zeng, Q., Engels, R., Galagan, J., Cuomo, C. A., Dobinson, K. F., and Ma, L.-J. 2011. Comparative genomics yields insights into niche adaptation of plant vascular wilt pathogens. PLoS Pathog 7:e1002137.

Knüfer, J., Lopisso, D. T., Koopmann, B., Karlovsky, P., and von Tiedemann, A. 2017. Assessment of latent infection with Verticillium longisporum in fieldgrown oilseed rape by qPCR. Eur. J. Plant Pathol. 147:819-831.

Lancashire, P. D., Bleiholder, H., van den Boom, T., Langelüddeke, P., Stauss, R. Weber, E., and Witzenberger, A. 1991. A uniform decimal code for growth stages of crops and weeds. Ann. Appl. Biol. 119:561-601.

Lopisso, D. T., Knüfer, J., Koopmann, B., and von Tiedemann, A. 2017a. Growth of Verticillium longisporum in xylem sap of Brassica napus is independent from cultivar resistance but promoted by plant aging. Phytopathology 107:1047-1054. 
Lopisso, D. T., Knüfer, J., Koopmann, B., and von Tiedemann, A. 2017b. The vascular pathogen Verticillium longisporum does not affect water relations and plant responses to drought stress of its host, Brassica napus. Phytopathology 107:444-454.

Maruthachalam, K., Klosterman, S. J., Anchieta, A., Mou, B., and Subbarao, K. V. 2013. Colonization of spinach by Verticillium dahliae and effects of pathogen localization on the efficacy of seed treatments. Phytopathology 103:268-280.

Nazar, R. N., Hu, X., Schmidt, J., Culham, D., and Robb, J. 1991. Potential use of PCR-amplified ribosomal intergenic sequences in the detection and differentiation of Verticillium wilt pathogens. Physiol. Mol. Plant Pathol. 39: $1-11$.

Nirenberg, H. 1976. Untersuchungen über die morphologische und biologische Differenzierung in der Fusarium-Sektion Liseola. Mitteilungen der Bio logischen Bundesanstalt für Land- und Forstwirtschaft 169:1-117.

Sackston, W. E. 2009. Some factors influencing infection of sunflower seed by Verticillium dahliae. Can. J. Plant Pathol. 2:209-212.

Sackston, W. E., McDonald, W. C., and Martens, J. 1957. Leaf mottle or Verticillium wilt of sunflower. Plant Dis. 41:337-343.

Short, D. P. G., Gurung, S., Koike, S. T., Klosterman, S. J., and Subbarao, K. V. 2015. Frequency of Verticillium species in commercial spinach fields and transmission of $V$. dahliae from spinach to subsequent lettuce crops. Phytopathology 105:80-90.

Snyder, W. C., and Wilhelm, S. 1962. Seed transmission of Verticillium wilt of spinach. Phytopathology 52:365.

U.S. Department of Agriculture. 2018. Oilseeds: World markets and trade. https:// apps.fas.usda.gov/psdonline/circulars/oilseeds.pdf.
Vallad, G. E., Bhat, R. G., Koike, S. T., Ryder, E. J., and Subbarao, K. V. 2005. Weedborne reservoirs and seed transmission of Verticillium dahliae in lettuce. Plant Dis. 89:317-324.

Weber, E., and Bleiholder, H. 1990. Erläuterungen zu den BBCH-Dezimal-Codes für die Entwicklungsstadien von Mais, Raps, Faba-Bohne, Sonnenblume und Erbse - mit Abbildungen. Gesunde Pflanzen 42:308-321.

Yu, S., Su, T., Chen, J., Wang, W., Zhang, F., Yu, Y., Zhang, D., Zhao, X., and Lu, G. 2015. Real-time PCR as a diagnostic tool for evaluating the resistance of Chinese cabbage cultivars to Verticillium wilt. Eur. J. Plant Pathol. 143:549-557.

Zeise, K., and von Tiedemann, A. 2001. Morphological and physiological differentiation among vegetative compatibility groups of Verticillium dahliae in relation to $V$. longisporum. J. Phytopathol. 149:469-475.

Zeise, K., and von Tiedemann, A. 2002. Host specialization among vegetative compatibility groups of Verticillium dahliae in relation to Verticillium longisporum. J. Phytopathol. 150:112-119.

Zhang, Y., Zhang, J., Gao, J., Zhang, G., Yu, Y., Zhou, H., Chen, W., and Zhao, J. 2018. The colonization process of sunflower by a green fluorescent proteintagged isolate of Verticillium dahliae and its seed transmission. Plant Dis. 102:1772-1778.

Zheng, X., Pfordt, A., Khatri, L., Eseola, A. B., Wilch, A., Koopmann, B., and von Tiedemann, A. 2019. Contrasting patterns of colonization with Verticillium longisporum in winter and spring type oilseed rape (Brassica napus L.) in the field and greenhouse and the role of soil temperature. Plant Dis. 103:2090-2099.

Zhou, L., Hu, Q., Johansson, A., and Dixelius, C. 2006. Verticillium longisporum and V. dahliae. Infection and disease in Brassica napus. Plant Pathol. 55:137-144. 